\title{
Centre-surround inhibition is a general aspect of famous- person recognition: Evidence from negative semantic priming from clearly visible primes
}

\author{
Anna Stone \\ Published online: 28 December 2011 \\ (C) Psychonomic Society, Inc. 2011
}

\begin{abstract}
A centre-surround attentional mechanism was proposed by Carr and Dagenbach (Journal of Experimental Psychology: Learning, Memory, and Cognition 16: 341$350,1990)$ to account for their observations of negative semantic priming from hard-to-perceive primes. Their mechanism cannot account for the observation of negative semantic priming when primes are clearly visible. Three experiments $\left(N_{\mathrm{s}}=30,46\right.$, and 30$)$ used a familiarity decision with names of famous people, preceded by a prime name with the same occupation as the target or with a different occupation. Negative semantic priming was observed at a $150-$ or $200-\mathrm{ms}$ SOA, with positive priming at shorter (50-ms) and longer (1,000-ms) SOAs. In Experiment 3, we verified that the primes were easily recognisable in the priming task at an SOA that yielded negative semantic priming, which cannot be predicted by the original centresurround mechanism. A modified version is proposed that explains transiently negative semantic priming by proposing that centre-surround inhibition is a normal, automatically invoked aspect of the semantic processing of visually presented famous names.
\end{abstract}

Keywords Negative semantic priming - Person recognition . Centre-surround $\cdot$ Inhibition $\cdot$ Memory retrieval .

Modification

The human ability to learn and to recall semantic information about a large number of known persons is essential to

\footnotetext{
A. Stone $(\square)$

School of Psychology, University of East London,

Stratford campus,

Water Lane,

Stratford, London, E15 4LZ, UK

e-mail: A.Stone@uel.ac.uk
}

our social existence. This semantic information is commonly believed to be stored in a network structure such that a node representing an individual person is connected to nodes representing items of semantic information about that person. These items of semantic information are also connected to other known individuals who share the same semantics. So, when a famous person is perceived, activation can spread from the node representing the person to the node representing, for example, their occupation, and then to the nodes of other persons with the same occupation, so that the recognition of these other famous persons is facilitated (e.g., Carson \& Burton, 2001; Stone \& Valentine, 2007).

Semantic priming occurs when the speed of response to a target is influenced by the prior presentation of a prime semantically related to that target. Semantic priming may arise between close associates (e.g., Brad Pitt and Angelina Jolie) or members of the same category (e.g., Brad Pitt and Johnny Depp have a common occupation). Categorical priming, typically using occupation as the shared category, has previously been reported in several investigations of famous-person recognition (e.g., Brennen \& Bruce, 1991; Bruce, 1983; Carson \& Burton, 2001; Stone \& Valentine, 2007).

Responses are usually faster to related than to unrelated targets, yielding positive semantic priming. However, under certain conditions - when primes were presented for very brief, masked exposures-Stone and Valentine (2007) observed negative semantic priming for famous names primed by an occupational category; that is, responses were systematically slower to related than to unrelated targets. This finding fits with previous observations of negative semantic priming for words (e.g., Carr \& Dagenbach, 1990; Dagenbach, Carr, \& Barnhardt, 1990; Dagenbach, Carr, \& Wilhelmsen, 1989; Frings, Bermeitinger, \& Wentura, 2008; Stolz \& Besner, 
1997; Wentura \& Frings, 2005) and for novel objects (Dagenbach \& Carr, 1994). Negative semantic priming can be explained by centre-surround theory, a brief description of which follows.

Carr and Dagenbach (1990) proposed a centre-surround attentional mechanism to account for their observations of negative semantic priming. This attentional mechanism is invoked when a participant attempts to extract into consciousness the meaning of a prime and this meaning is hard to extract. Difficulty in achieving awareness of the prime's semantics could arise either because the prime is weakly activated, as with masked priming (Dagenbach et al., 1989; Frings et al., 2008; Stone \& Valentine, 2007; Wentura \& Frings, 2005), or because the meaning itself is weakly activated, as with newly learned vocabulary words (Dagenbach et al., 1990) or novel and arbitrary object categories (Dagenbach \& Carr, 1994). The attentional mechanism boosts the degree of activation of the semantic code(s) representing the prime (i.e., the "centre"), and suppresses the degree of activation at other codes receiving some spreading activation from the prime (i.e., the "surround"). This helps to distinguish the semantic code(s) of the prime from surrounding codes, and thus helps to extract the meaning of the prime into awareness. If the attempt is successful, then the meaning of the prime crosses the threshold for conscious awareness, and spreading activation to related semantic codes ensures speeded responses to related itemsthat is, positive priming. When the attempt fails, however, the suppression of activation at related codes leads to slowed responses to related items, and hence to negative semantic priming. Carr and Dagenbach proposed that a necessary condition for the centre-surround attentional mechanism to operate is that awareness of the prime's semantics must be severely restricted, for otherwise there would be no need to invoke the attentional mechanism.

An important point is that centre-surround theory assumes a mechanism that has clearly been hypothesised as being invoked to deal with a word whose meaning is hard to extract into awareness. In this regard, it is intriguing that negative semantic priming has been observed from clearly visible primes (unpublished data): A group of 31 participants made a speeded familiarity decision to the name of a famous or nonfamous person, preceded by the name of a famous person with the same occupation as the famous target or with a different occupation. Primes were exposed for $150 \mathrm{~ms}$ without masking, so they were likely to have been clearly visible. The surprising result was that negative categorical priming was observed at a $150-\mathrm{ms}$ SOA, contrasting with nonsignificantly positive priming at a $1,000-\mathrm{ms}$ SOA. This observation of negative semantic priming from clearly visible primes cannot be accommodated within the original centre-surround hypothesis, so if this result proves to be replicable, either a modification to the current centre- surround mechanism or a new theory of negative semantic priming will be required.

The structure of the remainder of this article is as follows. Experiment 1 focused on a range of prime-target stimulus onset asynchronies (SOAs) in order to investigate the relationship between SOA or prime visibility and the direction of priming. Experiment 2 was designed to remove a potential confound from the design of Experiment 1 by controlling the stimulus energy at all levels of SOA. Then, Experiment 3 was designed to offer verification that the primes were indeed clearly recognisable at the SOA that produced negative priming. Finally, the General Discussion will consider how the centre-surround hypothesis might be modified to accommodate the results of these experiments and whether other accounts of semantic priming could offer an alternative explanation.

Experiment 1 investigated categorical priming from unmasked primes at SOAs of 50, 200, and 1,000 ms. At a 50 -ms SOA, the prediction was for positive categorical priming, as had been observed by Stone and Valentine (2007). Although that previous study included masking, whereas the present experiment did not, the effect of masking in the previous study should have been to reduce the magnitude of priming, so positive priming would be predicted under the more favourable, unmasked conditions of the present study. Negative priming was predicted at the 200-ms SOA, as in the unpublished pilot study in which this effect was observed. Positive priming was predicted at the 1,000-ms SOA, because this was sufficiently long to permit the operation of the strategic processes, including expectancy, that are a key component of semantic priming (e.g., Neely, 1977). Participants had ample opportunity to observe that pairs of stimuli were sometimes related by virtue of sharing an occupation, and Stone (2008) had demonstrated that this awareness is sufficient to produce positive priming at a $1,000-\mathrm{ms}$ SOA. According to a review by McNamara (2005, p. 155), strategic processes have a relatively strong effect under the conditions of a long SOA, a lexical decision (or analogous name familiarity) task, and category priming as compared to associative priming, so positive semantic priming was predicted in the $1,000-\mathrm{ms}$ condition of Experiment 1.

\section{Experiment 1}

Method

Participants There were 30 participants, 24 female and 6 male, with ages ranging from 23 to 53 (mean 37.2 years, $S D$ 7.7). All were undergraduate or postgraduate students of The Open University. 
Design The task was a familiarity decision to the name of a famous or a nonfamous person. The prime was always the name of a famous person, so that prime fame had no predictive validity for target response. A famous target was either from the same occupational category as the prime (related condition) or a different occupational category (unrelated condition). The unfamiliar targets were included only to generate the task demand. The primes were a separate set of names from the targets; that is, no prime name was repeated as a target.

There were two within-participants factors: Target Condition (related, unrelated, or unfamiliar) and Prime-Target SOA (50-ms prime exposure, followed immediately by the target; $150-\mathrm{ms}$ prime exposure with a 50 -ms blank screen, giving a 200-ms SOA; and 150-ms prime exposure with an 850 -ms blank screen, giving a 1,000-ms SOA). According to the review by McNamara (2005, p. 66), an SOA of $200 \mathrm{~ms}$ should be sufficiently brief to preclude substantial strategic processing.

The prime was followed by a blank screen (in the 200and 1,000-ms SOA conditions) rather than a mask. A mask could result in restricted awareness of the prime, and if so, this would constitute a test of the original centre-surround hypothesis - that is, of the hypothesis that an attentional mechanism is invoked to deal with hard-to-perceive primes. The purpose of the present series of experiments was to investigate whether centre-surround inhibition arises even with easy-to-perceive primes, so no mask was used.

Stimuli A total of 120 target names were used, 60 famous and 60 unfamiliar, as well as a separate set of 120 prime names, all of them famous, so that prime fame had no predictive value for the target response. None of the prime names were repeated as target names. The 60 famous target names were all paired with a prime name of the same occupational category and divided into six sets of 10 pairs, so that (as far as possible) each set had equal numbers of pairs from the different occupational categories. The six sets were rotated around the six experimental combinations of $\operatorname{SOA}(50,200$, or 1,000$)$ with relation (related or unrelated), so that each participant saw all of the six sets, and each set was used in each experimental condition approximately equal numbers of times. Unrelated sets were formed by repairing the related pairs in the set. See the Appendix for a list of the related sets. Thus, the primes and targets were counterbalanced in the related and unrelated conditions, and each item occurred in each experimental condition across participants, but only once for each participant. As a further precaution, counterbalancing was used as a grouping variable in the analyses, to make sure that there were no unintended effects.

The choice of target names was made in order to maximise the likelihood of recognition by the experimental participants. This indicated a large number of popular film actors (24 pairs), followed by pop musicians (12 pairs), as well as comedians (6), TV presenters (6), members of the U. K. royal family (past and present) (6), and smaller numbers of politicians (3) and film directors (3).

Procedure The participants performed the task alone in a quiet cubicle. The experimental trials were preceded by eight practice trials to ensure that participants were familiar with the task. The prime was displayed in the centre of the screen, followed after the SOA by the target, in the same screen position. Participants were asked to pay attention to the screen and to read the prime name but not to respond to it. They pressed one of two keys on the keyboard to indicate whether or not the target name was famous. The intertrial interval was $1 \mathrm{~s}$. Participants were not informed of any relationship between the prime and target names.

Verification of prime visibility The same stimuli were presented exactly as in the main experimental task to a separate group of pilot participants, who were asked to name the prime on each trial instead of responding to the target. Their responses were recorded by the experimenter and subsequently checked for accuracy. The first three pilot participants (all male; 20, 24, and 31 years of age) achieved very high scores, so no further data were collected. The numbers of primes missed at the $50-\mathrm{ms}$ SOA by the 3 participants were 6,12 , and 1 , for an average of $15.8 \%$; the numbers of primes missed at the 200-ms SOA were 3, 0, and 0, for an average of $2.5 \%$; and none of the participants missed any primes at $1,000-\mathrm{ms}$ SOA. This confirms that the primes were readily visible in general, and especially at the key SOA of $200 \mathrm{~ms}$ at which negative priming was predicted.

\section{Results}

The mean response time was calculated per participant for each combination of prime-target relation and SOA. An analysis of variance (ANOVA) was performed on the mean response times, with Stimulus Counterbalancing as a between-participants variable. The Greenhouse-Geisser correction was used due to violation of the assumption of sphericity. Significant interactions were investigated with paired-samples $t$ tests.

Data were excluded if the response was incorrect (5.3\% of responses) or slower than 2.5 standard deviations above the participant mean (2.9\% of responses). No responses were faster than $400 \mathrm{~ms}$. The means are presented in Fig. 1 and Table 1.

There was no main effect or interaction involving the factor of Stimulus Counterbalancing (all $F \mathrm{~s}<1.9$, n.s.). However, there was a significant interaction between SOA 


\section{Experiment 1}

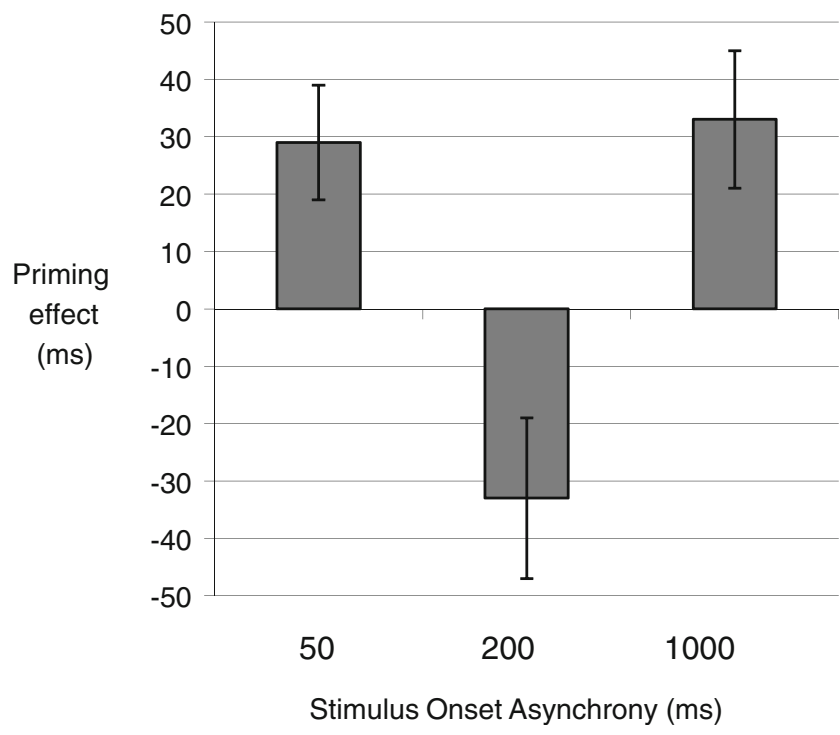

Fig. 1 Mean priming effects in Experiment 1, calculated as the differences between response times in the unrelated and related conditions. Bars represent the standard errors of the mean differences

and prime-target relation $[F(2,23)=11.24, p<.001]$. Paired-samples $t$ tests revealed that categorical priming was positive at the 50-ms SOA $[t(29)=2.84, p<.01]$, negative at the 200-ms SOA $[t(29)=2.30, p<.03]$, and positive again at the $1,000-\mathrm{ms} \mathrm{SOA}[t(30)=2.78, p<.01]$.

An ANOVA was also performed on the accuracy data, with the same factors. None of the effects were statistically significant (all $p \mathrm{~s}>.1$ ), offering no suggestion of a speedaccuracy trade-off. See Table 1.

\section{Discussion}

The pattern of results suggests that negative semantic priming of famous-person recognition at an SOA of $200 \mathrm{~ms}$ can arise when the meanings of primes are easy to extract into awareness. This contradicts a key assumption of the original centre-surround hypothesis of Carr and Dagenbach (1990).

There is, however, a limitation of the design of Experiment 1: The SOA conditions were not equated in terms of the stimulus energy of the prime. In the 200- and 1,000-ms SOA conditions, primes were presented for $150 \mathrm{~ms}$, whereas in the 50-ms condition they were only presented for $50 \mathrm{~ms}$. It could be argued that the change from positive priming at the 50-ms SOA to negative priming at the 200-ms SOA was due to the change in prime exposure, and the switch back to positive priming at the $1,000-\mathrm{ms}$ SOA was due to the increase in the SOA. Experiment 2 was designed to overcome this limitation.

\section{Experiment 2}

This was similar to Experiment 1, with primes presented for the same $25 \mathrm{~ms}$ in all conditions, with a blank screen between the prime and the target. The duration of the blank screen was varied in order to achieve the experimental manipulation of SOA.

\section{Method}

Participants There were 46 participants, 37 female and 9 male, with ages ranging from 18 to 52 (mean 25.3 years, $S D$ 8.8). None had taken part in the previous experiment, and all were undergraduate or postgraduate students of The Open University or the University of East London.

Design, materials, and procedure All of these aspects were the same as in Experiment 1, except that all primes were exposed for $25 \mathrm{~ms}$ and followed by a blank screen for 25 , 125 , or $975 \mathrm{~ms}$, creating total SOAs of 50,150 , or $1,000 \mathrm{~ms}$.
Table 1 Mean (and $S D$ s) of response times, measured in milliseconds, and proportions of errors in the different SOA conditions of Experiments 1, 2, and 3

\begin{tabular}{|c|c|c|c|c|c|c|}
\hline & \multicolumn{3}{|c|}{ Response Time } & \multicolumn{3}{|l|}{ Errors } \\
\hline & Exp. 1 & Exp. 2 & Exp. 3 & Exp. 1 & Exp. 2 & Exp. 3 \\
\hline \multicolumn{7}{|l|}{ 50-ms SOA } \\
\hline Same category mean $(S D)$ & 844 (99) & $910(163)$ & $1,237(246)$ & $.06(.09)$ & $.21(.18)$ & $.14(.11)$ \\
\hline Different category mean $(S D)$ & $872(107)$ & $936(179)$ & $1,285(251)$ & $.09(.09)$ & $.19(.15)$ & $.16(.13)$ \\
\hline \multicolumn{7}{|l|}{ 200-/150-ms SOA } \\
\hline Same category mean $(S D)$ & $886(107)$ & $918(174)$ & $1,233(235)$ & $.06(.08)$ & $.21(.19)$ & $.11(.12)$ \\
\hline Different category mean $(S D)$ & 853 (112) & $868(136)$ & $1,178(253)$ & $.06(.07)$ & $.24(.18)$ & $.14(.11)$ \\
\hline \multicolumn{7}{|l|}{$1,000-\mathrm{ms} \mathrm{SOA}$} \\
\hline Same category mean $(S D)$ & $803(120)$ & $856(173)$ & $1,047(187)$ & $.07(.08)$ & $.23(.18)$ & $.16(.14)$ \\
\hline Different category mean $(S D)$ & $836(122)$ & $884(158)$ & $1,089(242)$ & $.07(.10)$ & $.23(.18)$ & $.13(.11)$ \\
\hline
\end{tabular}


Results

Mean response times were calculated per participant for each combination of prime-target relation (related vs. unrelated) and $\operatorname{SOA}(50,150$, or 1,000 ms). An ANOVA was performed on the mean response times, with these two within-participants factors and Stimulus Counterbalancing as a between-participants factor, using the GreenhouseGeisser correction for violation of the assumption of sphericity. Significant interactions were investigated with pairedsamples $t$ tests.

Data were excluded if the response was incorrect (15.8\% of responses), slower than 2.5 standard deviations above the participant mean $(2.8 \%$ of responses), or faster than $400 \mathrm{~ms}$ (less than $1 \%$ of responses). The means are presented in Fig. 2 and Table 1.

The main effect of SOA was significant $[F(2,39)=4.82$, $p<.05]$, showing mean responses becoming faster as the SOA increased. This was probably due to the increasing utility of the prime as a cue for the onset of the target. There was no significant main effect or interaction involving the factor of Stimulus Counterbalancing [all $F_{\mathrm{S}}<1.5, p \mathrm{~s}>.2$ ]. As predicted, the two-way interaction of SOA and relation was significant $[F(2,39)=8.25, p<.005]$. Paired-samples $t$ tests examined priming at each SOA. At the 50-ms SOA, priming of $+26 \mathrm{~ms}$ was significant $[t(45)=2.15, p<.05]$; at the $150-\mathrm{ms} \mathrm{SOA}$, priming of $-50 \mathrm{~ms}$ was significant $[t(45)=$ $3.16, p<.005]$; and at the $1,000-\mathrm{ms} \mathrm{SOA}$, priming of $28 \mathrm{~ms}$ was significant $[t(45)=1.77, p<.05$, one-tailed].

An ANOVA on the accuracy data with the three factors of SOA, Prime-Target Relation, and Stimulus Counterbalancing revealed no statistically significant effects (all $p \mathrm{~s}>.1$ ), offering no suggestion of a speed-accuracy trade-off.
Discussion

This experiment confirmed the observation of transient negative semantic priming in a design in which the prime exposure duration, and thus stimulus energy, was equated across all SOA conditions, and in which the sequence of presentation of the prime, then a blank screen, and then target was the same for all SOAs. The results rule out the possibility that the change in the direction of priming in Experiment 1 with increasing SOA could have been caused by the difference in stimulus energy.

However, another potential problem was that the prime visibility study of Experiment 1 was done with a different set of participants, and that when they tested the visibility of the prime they were not also required to respond to the target on the same trial. This would have made it easier to focus and concentrate on the prime, so the prime might have been more visible in the prime visibility task than it was in the actual priming task. If this was the case, it could be argued that the negative categorical priming observed at a $200-\mathrm{ms}$ SOA (Exp. 1) or a 150-ms SOA (Exp. 2) in the priming task might be a result of inability to perceive the prime that resulted from a lack of attention. Experiment 3 was designed to investigate this alternative explanation.

\section{Experiment 3}

The purposes of Experiment 3 were (a) to check whether the same pattern of positive priming at a $50-\mathrm{ms}$ SOA, negative priming at a $150-\mathrm{ms} \mathrm{SOA}$, and positive priming at a 1,000ms SOA would be observed when the participants were forced to attend to the prime, and (b) to offer evidence that

\section{Experiment $2 \quad$ Experiment 3}

Experiments 2 and 3, calculated as the differences in response times between the unrelated and related conditions. Bars represent standard errors of the mean differences

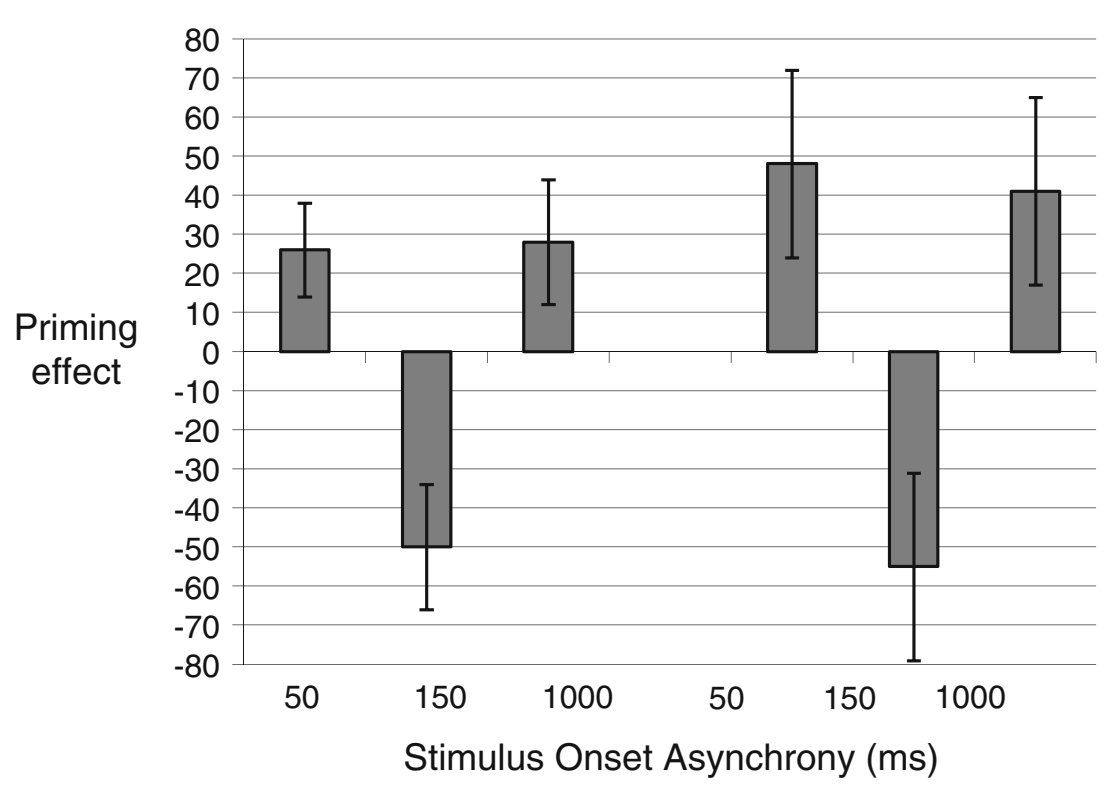


the prime was clearly visible and that its relevant semantics were readily retrieved within the priming task itself and with the same group of participants.

Experiment 3 used a dual-task paradigm, in which participants were asked to respond to either the prime or the target on each trial, where the type of response required varied pseudorandomly between trials. In this way, the two tasks of prime visibility and target response were tested under the same conditions and with the same participants. At the start of each trial, and while the prime was presented, participants did not know to which stimulus they would be asked to respond, so they were compelled to pay attention to the prime. If the prime was found to be clearly visible and its relevant semantics to be readily activated under these conditions, and if negative semantic priming was observed at the intermediate level of SOA, this would confirm that transient negative semantic priming can be observed from clearly visible primes.

\section{Method}

Participants There were 30 participants, 22 female and 8 male, with ages ranging from 23 to 47 (mean 34.3 years, $S D$ 6.7). None had taken part in the previous experiments, and all were undergraduate or postgraduate students of The Open University or the University of East London.

Design, materials, and procedure All aspects were the same as in Experiment 2, except for the following details.

The main difference was that participants were asked to respond to either the prime or the target on each trial, pseudorandomly organised so that there were equal numbers of responses to the prime and the target. After the prime was presented, either the target or an instruction to respond to the prime would appear. Thus, only when the second stimulus was presented did participants discover whether they should respond to the prime or the target. To facilitate this design, the response to the prime was to specify whether or not the person was an actor (a similar method had been used by Huber, Clark, Curran, \& Winkielman, 2008), so that the response to the prime was a simple binary "yes" or "no," as was the response to the target. The response to the prime required the recognition of the famous name and the retrieval of the item of semantic information representing the person's occupation; this was the aspect of semantics implemented in the design of the related and unrelated conditions.

All primes were exposed for $25 \mathrm{~ms}$, followed by a blank screen $(25,125$, or $975 \mathrm{~ms})$ for the remainder of the SOA, as in Experiment 2, and then followed by the second stimulus. There were two conditions: If the second stimulus was the target, it was presented slightly higher on the screen and in a green colour, and participants made a fame decision, as before. If the second stimulus was the prompt "actor?" presented in the same screen location as the prime, then participants responded to the prime with a binary "yes" or "no" decision. Thus, the same response keys were used to respond to the prime or to the target. Each prime was presented twice, once for a prime visibility test, and one for a target response.

\section{Results}

Responses to primes Responses to the prime were $87.9 \%$ accurate, which compared very closely with the $87.5 \%$ accuracy for responses to the target, and was slightly better than the accuracy in Experiment 2. This suggests that the primes were at least as readily visible as the targets and, given that the targets were presented on the screen until the participant responded, this suggests that the primes were readily visible. Any shortfall in correct responses to the primes seems likely to have been due to a genuine lack of familiarity with the famous person or to random error. It is also relevant to note that the task on the prime was a decision about the corresponding occupation, so this demonstrates that the relevant semantics were readily retrieved from memory.

Responses to the primes were of equivalent accuracy at each SOA, so there was no evidence that primes were especially difficult to perceive at the intermediate $150-\mathrm{ms}$ SOA at which negative semantic priming was predicted. The mean accuracies of responses to the prime were $86.5 \%(S D 7.1)$ at the $50-\mathrm{ms} \mathrm{SOA}, 88.0 \%(S D 7.3)$ at the 150-ms SOA, and $89.3 \%(S D 7.6)$ at the 1,000-ms SOA. An ANOVA with repeated measures on SOA showed no significant differences in the accuracies of prime responses $[F(2$, 28) $=1.42$, n.s.].

Responses to targets The mean target response time was calculated per participant for each combination of primetarget relation and SOA (on only those trials on which a response was made to the target). Responses were excluded if the response to the target was incorrect $(12.5 \%$ of responses), slower than 2.5 standard deviations above the participant mean (1.5\% of responses), or faster than $400 \mathrm{~ms}$ (none). The means are presented in Fig. 2 and Table 1.

An ANOVA was performed with the two factors SOA $(50,150$, or $1,000 \mathrm{~ms})$ and Prime-Target Relation (related or unrelated) on the mean response times, with Stimulus Counterbalancing as a third, between-participants factor. Significant interactions were investigated with paired-samples $t$ tests. The Greenhouse-Geisser correction was used for violations of the assumption of sphericity.

The main effect of SOA was significant $[F(2,23)=$ $33.43, p<.001$ ], showing mean responses becoming faster as the SOA increased. This was likely due to the increasing 
utility of the prime as a cue for the onset of the target. There was no significant effect involving the factor of Stimulus Counterbalancing (all $F \mathrm{~s}<2, p \mathrm{~s}>1.2$ ). As predicted, the interaction of SOA and prime-target relation was significant $[F(2,38)=6.50, p<.01]$, and paired-samples $t$ tests examined priming at each SOA. At the 50-ms SOA, priming of $+48 \mathrm{~ms}$ was significant in a one-tailed test $[t(29)=1.98, p<.05]$; at the 150 -ms SOA, priming of $-55 \mathrm{~ms}$ was significant $[t(29)=2.32$, $p<.05]$; and at the 1,000-ms SOA, priming of $41 \mathrm{~ms}$ was significant in a one-tailed test $[t(29)=1.72, p<.05]$.

An ANOVA was performed on the accuracy data, with the same three factors of SOA, Prime-Target Relation, and Stimulus Counterbalance. No effects were significant (all $p \mathrm{~s}>.1$ ), offering no suggestion of a speed-accuracy trade-off.

\section{Discussion}

Responses to the primes were as accurate as responses to the targets. Since the former required retrieval of the prime person's occupation, there is no evidence that participants were unable to retrieve the relevant semantics of the primes. The design ensured that participants paid equivalent attention to the primes on all trials, so it can be safely concluded that the primes were attended and that their semantics were readily retrieved on trials in which participants responded to the target. This confirms the observation of transient negative semantic priming from clearly visible primes, which contradicts a key assumption of the centre-surround attentional mechanism theory.

\section{General discussion}

Negative categorical priming was observed at a $200-\mathrm{ms}$ SOA in Experiment 1 and at a 150-ms SOA in Experiments 2 and 3; responses were slower when the target person had the same occupation as the person in the prime, rather than a different occupation. This contrasts with positive categorical priming at the longer SOA of 1,000 ms and at the shorter $\mathrm{SOA}$ of $50 \mathrm{~ms}$. An additional check in Experiment 3 confirmed that primes were clearly visible at all SOAs and that their relevant semantics were readily retrieved. Experiment 2 ruled out a possible explanation based on differing stimulus energy, to focus on SOA as the primary influence on the direction of categorical semantic priming.

Several theories of semantic priming can only account for positive priming, so they are not candidates for explaining the present set of results: These include the spreading activation models proposed by Quillian (1967) and by Collins and Loftus (1975), Becker's (1980) verification model, compound-cue models (Ratcliff \& McKoon, 1988), and distributed network models (e.g., McClelland \& Rumelhart,
1985). In addition, the paradigm of negative priming from ignored distractors (e.g., Milliken, Joordens, Merikle, \& Seiffert, 1998) cannot account for negative semantic priming under the conditions of the present experiments, with only one prime and one target on each trial and no prime repeated as a target.

Other theories that could, potentially, explain the present observations of negative semantic priming will be examined.

Negative compatibility effect

In experiments by Schlaghecken, Bowman, and Eimer (2006), the prime and target stimuli were arrows pointing to either the right or left, and the required response was a keypress with the corresponding hand. At longer SOAs, the responses were faster when the prime and target were incompatible than when they were compatible, which was termed the negative compatibility effect, in contrast to a positive compatibility effect at very short SOAs. Schlaghecken et al.'s explanation was based on inhibition of a response to the prime that takes some short time to develop. The negative compatibility effect does not appear to apply in the present study, as its application is limited to experimental designs in which the target response is primed, whereas in the present series of experiments the target response was a fame decision, but all of the primes were famous names, and priming arose from the semantics of the prime.

\section{False-fame illusion}

In the "false-fame" illusion of Jacoby, Kelley, Brown, and Jasechko (1989), a person's name is read without attention so that on a later occasion, it cannot be consciously recalled. However, if the name is perceived later, it might be falsely identified as a famous name, because it engenders a feeling of familiarity in the absence of conscious recollection of a prior perceptual episode. If this idea is applied to the present experiments, a briefly presented 50-ms prime might invoke some activation of the occupational category, but without conscious awareness, and if the target has the same occupational category, the misattribution of the category from prime to target might facilitate a familiarity response to the target. Conscious awareness of the prime name at a $150-\mathrm{ms}$ SOA could potentially explain the disappearance of positive priming at this SOA. However, there is no apparent mechanism whereby this could produce a negative semantic priming effect at a $150-\mathrm{ms}$ SOA, nor a return to positive semantic priming at a $1,000-\mathrm{ms}$ SOA.

\section{ROUSE theory}

The "responding optimally with unknown sources of evidence" (ROUSE) model was proposed by Huber, Shiffrin, 
Lyle, and Ruys (2001) and was applied to a neural habituation model by Huber (2008). In a task involving the perceptual identification of briefly presented words, positive repetition priming was observed with prime exposure of up to $150 \mathrm{~ms}$, and negative repetition priming at durations of $400 \mathrm{~ms}$ or more. A key element of the theory is that the neural representations of the prime and of its semantics will habituate after a certain processing duration. At a short SOA, the prime's semantics are still activated when a related target is presented, providing facilitation to the processing of the target and positive priming. After a longer prime exposure, the prime's semantics are habituated, so that the processing of a related target is inhibited and there is negative semantic priming.

It is unclear whether the ROUSE theory with neural habituation can be applied to the present results. Huber (2008) attributed negative repetition priming to habituation of the visual features of the primes after $400 \mathrm{~ms}$. Given that semantics would likely take longer to activate and longer to habituate than visual features (Huber, 2008, p. 328) it is not clear that ROUSE can explain negative semantic priming after a $200-\mathrm{ms}$ SOA. Also, it is not clear that ROUSE could explain the third phase of positive semantic priming; such an explanation would rely on recovery from neural habituation, and it is not clear that this could occur with a 1,000 ms SOA.

\section{Psychophysical account of contrast effects}

This account was proposed by Klauer, Teige-Mocigemba, and Spruyt (2009) to account for contrast effects (conceptually similar to negative priming) in affective priming studies. According to this account, a "counter" records the rise in activation at a particular concept representation-for instance, there are counters for positive and for negative valence. The ease of categorisation of a stimulus as positive or negative depends on the rise in value of the corresponding counter during a particular time window. If a prime and target are presented close together, the activation induced by the prime is included within the time window of the target, thus boosting the apparent rise in the counter for a compatible target, so that positive priming results. If there is a longer delay between prime and target, the activation induced by the prime is not included within the window for the target. The counter for a compatible target rises more slowly if it is already somewhat activated by the prime, as compared to a counter not already activated by the prime, so that it is easier to detect a contrasting target, and negative priming results.

This account could be applied to the present series of experiments by replacing the idea of the counter for affective valence with a counter for occupation. However, there does not appear to be any way to explain the third phase of priming - that is, a return to positive priming with a longer SOA.

Centre-surround inhibition

The centre-surround attentional mechanism of Carr and Dagenbach (1990) was described in the introduction. Carr and Dagenbach proposed that a necessary condition for the centre-surround attentional mechanism is that awareness of the prime's semantics must be severely restricted, for otherwise there is no need to invoke the attentional mechanism. Experiment 3 in the present series demonstrated that the primes were clearly perceptible and that their relevant semantics were retrievable, so this condition was not met.

A modified centre-surround mechanism is proposed here that is conceived of as being invoked automatically rather than strategically, as a normal feature of the semantic processing of person names, so that it is not necessary for primes to be hard to perceive or for their semantics to be hard to retrieve. Indeed, Barnhardt, Glisky, Polster, and Elam (1996) and Wentura and Frings (2005) have already suggested that centre-surround inhibition is invoked automatically rather than strategically. The modified mechanism overcomes a second drawback of the original centre-surround attentional mechanism, which is that it seems implausible for the visual processing system to decide that the meaning of a stimulus is hard to retrieve into awareness within the timings that have been observed to produce negative semantic priming (e.g., SOAs of $217 \mathrm{~ms}$ in Stone \& Valentine, 2007; $260 \mathrm{~ms}$ in Frings et al., 2008; and $280 \mathrm{~ms}$ in Wentura \& Frings, 2005).

\section{Modified centre-surround mechanism}

The proposed mechanism of centre-surround inhibition works in this way. When a person name is presented [Time (a) in Fig. 3], activation spreads to codes representing the names of related persons [Time (b)] and positive priming may be observed. After a short delay, within-pool inhibition begins to be applied by the prime name to the names of related persons [Time (c)], to ensure that the identification of a seen name inhibits the simultaneous identification of other names. The effect is that the names of categorically related persons may be below their resting level of activation [between Times (c) and (d)], and negative priming may be observed. If visual input is sustained, the activation at the prime name continues to rise, and the activation at related names rises again above resting level, while still maintaining a differential below the prime name [Time (d) onwards]. In the later time window, positive priming may be observed.

Consistent with this reasoning is the observation by Alario, Segui, and Ferrand (2000) of negative priming from clearly visible primes at a 114-ms SOA, and then a null 


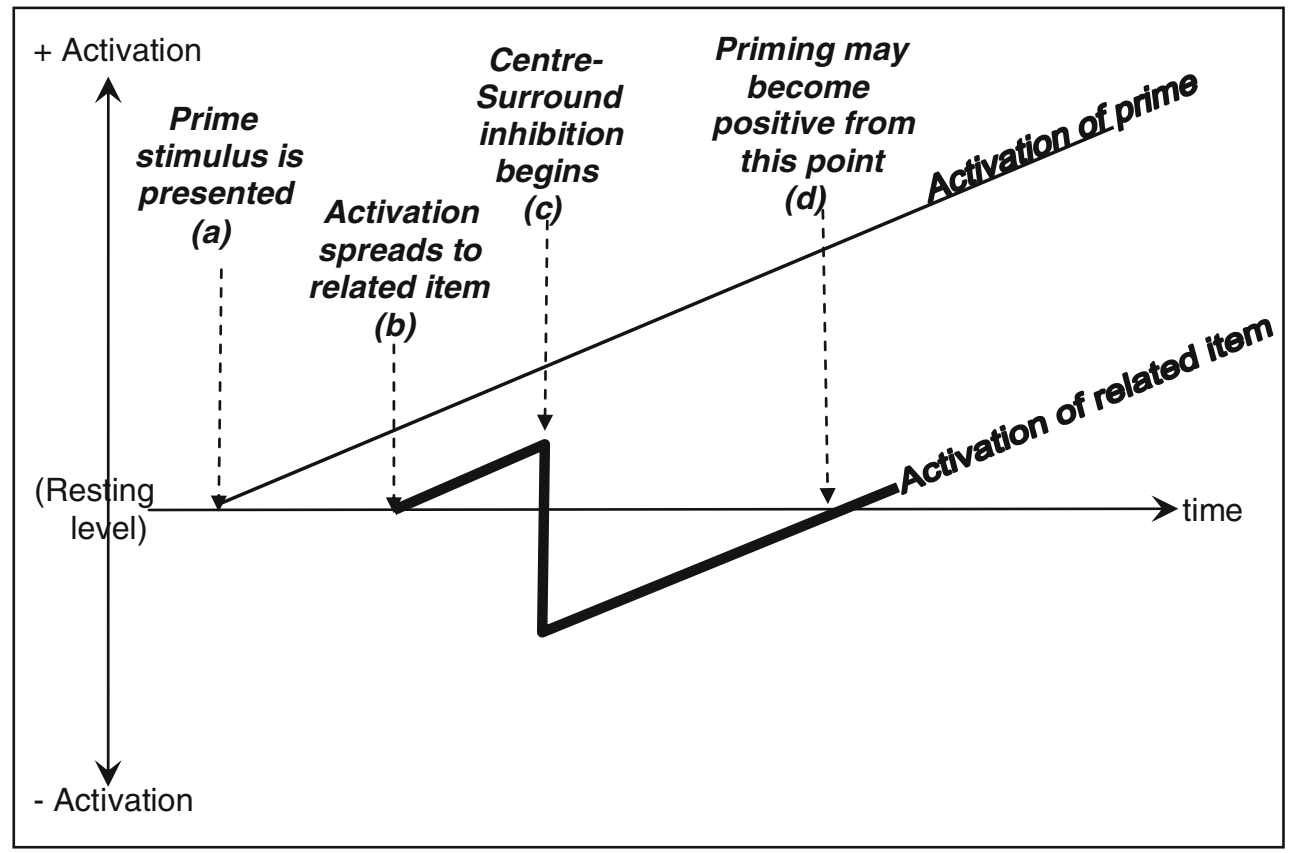

Fig. 3 Conceptual representation of the proposed modified mechanism of centre-surround inhibition in the categorical priming of famous names. Between Times (a) and (b), there is no priming of responses to a related name; between Times (b) and (c), activation of the related name is above resting level, and positive priming may be observed; between Times (c)

priming effect at a longer SOA of $234 \mathrm{~ms}$; an SOA longer than this was not tested, so we do not know whether priming would have become positive in direction.

If this modified form of centre-surround inhibition is part of the normal visual processing of famous names, this begs the question of why negative semantic priming from clearly visible primes is not more commonly observed. There are three plausible answers to this question. (1) Negative priming can be observed only for items that are relatively weakly activated by spreading activation from the prime stimulusfor instance, members of the same category that are not repeated during the experimental task (or masked and briefly exposed primes, or visible primes whose meanings are hard to retrieve). In contrast, unmasked and highly familiar close associates, or targets used repeatedly, will be more strongly activated by spreading activation from the prime. Although the centre-surround mechanism will still operate, it will not drive the level of activation of these targets below their resting level, so there will be no observed effect of negative priming. (2) Negative priming from clearly visible primes can be observed only for a certain time window, so studies using a longer SOA will not observe negative priming. (3) Negative priming may indeed have been observed in previous studies, but in the absence of an explanation, it might have been interpreted as a null priming effect.

It could be argued that, in order to claim that centresurround inhibition is automatic, the experimental design and (d), activation of the related name is below resting level, and negative priming may be observed; after Time (d), activation of the related name is above resting level, and priming may become positive once again. Centre-surround inhibition is shown as having an immediate rather than a gradual effect for representational simplicity

should hold SOA constant while varying the aspect of prime visibility - for example, by using a mixture of masked and unmasked trials. Priming could be compared between trials in which the prime was recognised and trials in which it was not recognised for a fixed SOA. If equivalent degrees of priming were to be observed, this would indeed establish that centre-surround inhibition occurs whether or not the prime is visible. The problem with this argument, however, is that if different degrees of priming were to be observed for masked and unmasked primes, this could be related to the difference in stimulus energy and would not necessarily be informative about the presence or absence of a centre-surround process. ${ }^{1}$

The present study has reported negative categorical priming from clearly visible primes only in the domain of famous person names. There is some evidence that knowledge for famous persons is structured similarly to word and object

\footnotetext{
${ }^{1}$ It is relevant to note that the negative categorical priming of $33 \mathrm{~ms}$ in the present Experiment 1 was similar to the negative categorical priming of $24 \mathrm{~ms}$ in Experiment 2 of Stone and Valentine (2007), in which famous faces were used instead of famous names. In the present Experiment 1, primes were presented for $150 \mathrm{~ms}$, followed by a blank screen for $50 \mathrm{~ms}$, and in the previous study, primes were presented for $17 \mathrm{~ms}$ and followed by a mask for $200 \mathrm{~ms}$ (i.e., SOAs of 200 vs. 217 $\mathrm{ms})$. This does tend to suggest that negative categorical priming of famous persons depends more on a particular SOA than on prime visibility, although the comparison of two separate experiments does limit the strength of the conclusions that can be drawn.
} 
knowledge (e.g., Carson \& Burton, 2001; Darling \& Valentine, 2005; Stone \& Valentine, 2007), so similar results might be predicted in these domains. Future studies could confirm whether the modified centre-surround mechanism appears to operate in other domains of semantic knowledge, but this investigation was outside the scope of the present study.

In conclusion, the present study has supported the key function of centre-surround inhibition - that is, helping to distinguish a perceived stimulus from related items in the semantic neighbourhood. Three experiments offered evidence that centre-surround inhibition may be a normal, automatically invoked part of the semantic processing of visual stimuli.

\section{Appendix}

Stimuli in Experiments 1, 2, and 3

Table 2 These are the prime-target pairs from the same occupational category. Pairs with different occupations were formed by shuffling these pairs

$\begin{array}{ll}\text { Film actors } & \\ \text { Leonardo DiCaprio \& } & \text { Orlando Bloom \& Samuel L. } \\ \text { Wesley Snipes } & \text { Jackson } \\ \text { Hugh Jackman \& Daniel Craig } & \text { Ben Affleck \& Cameron Diaz } \\ \text { Heath Ledger \& Nicholas Cage } & \text { Katie Holmes \& Robert di Niro } \\ \text { Catherine Zeta-Jones \& } & \text { Angelina Jolie \& Jim Carrey } \\ \text { Humphrey Bogart } & \text { Marilyn Monroe \& Matt } \\ \text { Denzel Washington \& } & \text { Damon } \\ \text { Kate Winslet } & \text { Bruce Willis \& Sharon Stone } \\ \text { Jude Law \& Sandra Bullock } & \text { Sigourney Weaver \& George } \\ \text { Kevin Spacey \& Clint Eastwood } & \text { Clooney } \\ & \text { Keira Knightly \& John Travolta } \\ \text { Gwyneth Paltrow \& Harrison Ford } & \text { Michael Douglas \& Nicole } \\ \text { Keanu Reeves \& Michelle Pfeiffer } & \text { Kidman } \\ \text { Uma Thurman \& Will Smith } & \text { Scarlett Johansson \& Brad Pitt } \\ \text { Al Pacino \& Hugh Grant } & \text { Tom Cruise \& Liz Hurley } \\ \text { Jodie Foster \& Mel Gibson } & \text { Halle Berry \& Pierce Brosnan } \\ \text { Film directors } & \\ \text { Ridley Scott \& Alfred Hitchcock } & \text { Walt Disney \& Steven } \\ \text { Francis Ford Coppola \& } & \text { Spielberg } \\ \text { Quentin Tarantino } & \\ \text { Comedy } & \\ \text { John Cleese \& David Walliams } & \text { Neil Morrissey \& Angus } \\ \text { Matt Lucas \& Victoria Wood } & \text { Deayton } \\ \text { Jack Dee \& Billy Connolly } & \text { Gervais } \\ \text { Popular music } & \text { Martin Clunes \& Dawn French } \\ \text { Missy Elliott \& Sean Combs } & \\ \text { Britney Spears \& Gwen Stefani } & \text { Kylie Minogue \& Posh Spice } \\ & \\ & \\ & \end{array}$

Mariah Carey \& Will Young

Noel Gallagher \& Madonna

Christina Aguilera \& Justin Timberlake

Michael Jackson \& Tina Turner

Royal characters

Prince Charles \& Henry the Eighth

Prince Albert \& Anne Boleyn

Prince William \& Camilla ParkerBowles

TV presenters

Michael Parkinson \& Bill Oddie

David Attenborough \& Trevor McDonald

Richard Madeley \& Simon Cowell

Politicians

Gordon Brown \& David Cameron

Bill Clinton \& Tony Blair
Robbie Williams \& Janet Jackson

Elvis Presley \& Whitney Houston

Lionel Ritchie \& Mick Jagger

Jimi Hendrix \& Bob Marley

Kate Middleton \& Diana Spencer

Prince Andrew \& Queen Elizabeth

Prince Philip \& Queen Victoria

Judy Finnegan \& Sharon Osborne

Phillip Schofield \& Anne Robinson

Oprah Winfrey \& Cilla Black

Margaret Thatcher \& George Bush

\section{References}

Alario, F.-X., Segui, J., \& Ferrand, L. (2000). Semantic and associative priming in picture naming. Quarterly Journal of Experimental Psychology, 53A, 741-764. doi:10.1080/027249800410535

Barnhardt, T. M., Glisky, E. L., Polster, M. R., \& Elam, L. (1996). Inhibition of associates and activation of synonyms in the rareword paradigm: Further evidence for a center-surround mechanism. Memory \& Cognition, 24, 60-69.

Becker, C. A. (1980). Semantic context effects in visual word recognition: An analysis of semantic strategies. Memory \& Cognition, $8,493-512$.

Brennen, T., \& Bruce, V. (1991). Context effects in the processing of familiar faces. Psychological Research, 53, 296-304. doi:10.1007/BF00920483

Bruce, V. (1983). Recognizing faces. Philosophical Transactions of the Royal Society B, 302, 423-436.

Carr, T. H., \& Dagenbach, D. (1990). Semantic priming and repetition priming from masked words: Evidence for a center-surround attentional mechanism in perceptual recognition. Journal of Experimental Psychology: Learning, Memory, and Cognition, 16, 341-350. doi:10.1037/0278-7393.16.2.341

Carson, D. R., \& Burton, A. M. (2001). Semantic priming of person recognition: Categorical priming may be a weaker form of the associative priming effect. Quarterly Journal of Experimental Psychology, 54A, 1155-1179.

Collins, A. M., \& Loftus, E. F. (1975). A spreading-activation theory of semantic processing. Psychological Review, 82, 407-428. doi:10.1037/0033-295X.82.6.407

Dagenbach, D., \& Carr, T. H. (1994). Inhibitory processes in perceptual recognition: evidence for a centre-surround attentional mechanism. In D. Dagenbach \& T. H. Carr (Eds.), Inhibitory processes in attention, memory and language. San Diego, CA: Academic Press. 
Dagenbach, D., Carr, T. H., \& Barnhardt, T. M. (1990). Inhibitory semantic priming of lexical decisions due to failure to retrieve weakly activated codes. Journal of Experimental Psychology: Learning, Memory, and Cognition, 16, 328-340. doi:10.1037/ 0278-7393.16.2.328

Dagenbach, D., Carr, T. H., \& Wilhelmsen, A. L. (1989). Task-induced strategies and near-threshold priming: Conscious influences on unconscious perception. Journal of Memory and Language, 28, 412-443. doi:10.1016/0749-596X(89)90020-X

Darling, S., \& Valentine, T. (2005). The categorical structure of semantic memory for famous people: A new approach using release from proactive interference. Cognition, 96, 35-65.

Frings, C., Bermeitinger, C., \& Wentura, D. (2008). Center-surround or spreading inhibition: Which mechanism caused the negative effect from repeated masked semantic primes? Experimental Psychology, 55, 234-242.

Huber, D. E. (2008). Immediate priming and cognitive aftereffects. Journal of Experimental Psychology. General, 137, 324-347. doi:10.1037/0096-3445.137.2.324

Huber, D. E., Clark, T. F., Curran, T., \& Winkielman, P. (2008). Effects of repetition priming on recognition memory: Testing a perceptual fluency-disfluency model. Journal of Experimental Psychology: Learning, Memory, and Cognition, 34, 1305-1324. doi:10.1037/ a0013370

Huber, D. E., Shiffrin, R. M., Lyle, K. B., \& Ruys, K. I. (2001). Perception and preference in short-term word priming. Psychological Review, 108, 149-182. doi:10.1037/0033-295X.108. 1.149

Jacoby, L. L., Kelley, C., Brown, J., \& Jasechko, J. (1989). Becoming famous overnight: Limits on the ability to avoid unconscious influences of the past. Journal of Personality and Social Psychology, 56, 326-338.

Klauer, K. C., Teige-Mocigemba, S., \& Spruyt, A. (2009). Contrast effects in spontaneous evaluations: A psychophysical account. Journal of Personality and Social Psychology, 96, 265-287.

McClelland, J. L., \& Rumelhart, D. E. (1985). Distributed memory and the representation of general and specific information. Journal of
Experimental Psychology. General, 114, 159-188. doi:10.1037/ 0096-3445.114.2.159

McNamara, T. P. (2005). Semantic priming: Perspectives from memory and word recognition. Hove, U.K.: Psychology Press.

Milliken, B., Joordens, S., Merikle, P. M., \& Seiffert, A. E. (1998). Selective attention: A reevaluation of the implications of negative priming. Psychological Review, 105, 203-229. doi:10.1037/0033295X.105.2.203

Neely, J. H. (1977). Semantic priming and retrieval from lexical memory: Roles of inhibitionless spreading activation and limited-capacity attention. Journal of Experimental Psychology. General, 106, 226-254. doi:10.1037/0096-3445.106.3.226

Quillian, M. R. (1967). Word concepts: A theory and simulation of some basic semantic capabilities. Behavioral Science, 12, 410-430.

Ratcliff, R., \& McKoon, G. (1988). A retrieval theory of priming in memory. Psychological Review, 95, 385-408. doi:10.1037/0033295X.95.3.385

Schlaghecken, F., Bowman, H., \& Eimer, M. (2006). Dissociating local and global levels of perceptuo-motor control in masked priming. Journal of Experimental Psychology. Human Perception and Performance, 32, 618-632. doi:10.1037/0096-1523.32.3.618

Stolz, J. A., \& Besner, D. (1997). Visual word recognition: Effort after meaning but not (necessarily) meaning after effort. Journal of Experimental Psychology. Human Perception and Performance, 23, 1314-1322. doi:10.1037/0096-1523.23.5.1314

Stone, A. (2008). Categorical priming of famous person recognition: A hitherto overlooked methodological factor can resolve a longstanding debate. Cognition, 108, 874-880. doi:10.1016/j. cognition.2008.06.001

Stone, A., \& Valentine, T. (2007). The categorical structure of knowledge for famous people (and a novel application of Centre-Surround theory). Cognition, 104, 535-564. doi:10.1016/j. cognition.2006.07.014

Wentura, D., \& Frings, C. (2005). Repeated masked category primes interfere with related exemplars: New evidence for negative semantic priming. Journal of Experimental Psychology: Learning, Memory, and Cognition, 31, 108-120. doi:10.1037/0278-7393.31.1.108 